\title{
The General Status of Animal Welfare in Developing Countries: The Case of Ethiopia
}

\section{Getahun Asebe $^{1^{*}}$, Bizelew Gelayenew ${ }^{1}$ and Ashwani Kumar ${ }^{2}$}

${ }^{1}$ Department of Animal Science, College of Agriculture and Natural Resource, Gambella University, PO Box 126, Gambella, Ethiopia

${ }^{2}$ Department of Veterinary Microbiology, Immunology and Public Health, College of Veterinary Medicine and Agriculture, Addis Ababa University, PO Box 34, Bishofitu/ Debre Zeit, Ethiopia

"Corresponding author: Getahun Asebe, Department of Animal Science, College of Agriculture and Natural Resource, Gambella University, PO Box 126, Gambella, Ethiopia, Tel: +251912470111; E-mail: getahunasebe@gmail.com

Rec date: Mar 25, 2016; Acc date: Apr 27, 2016; Pub date: Apr 29, 2016

Copyright: ( 2016 Asebe G, et al. This is an open-access article distributed under the terms of the Creative Commons Attribution License, which permits unrestricted use, distribution, and reproduction in any medium, provided the original author and source are credited.

\begin{abstract}
It is true most proportions of Africans livestock owners do not realize as animals are sensitive to beatings and mistreatment. As any African countries, Ethiopia has not formulated regular ways of awareness creation to the public and is not endorsed to the community what the minimal animal welfare standards to be esteemed. The issues of animal welfare in Ethiopia go to King Minilk II, yet the country lack practicing and enforcing the laws until present time. Despite the fact huge number of livestock present in the country, welfare not well kept, hence poor productivity and production is a common feature of the sector. Respecting the five freedoms of animals at least can help to secure the minimum standards of respecting animals' right. Freedom from hunger and thirst, discomfort, pain, injury, disease, fear, distress and freedom to express normal behavior are the known five rights. The marketing places, during transporting, farming places, slaughtering houses, feeding areas, sheltering areas and watering places are the commonest areas where welfare deprived. Except equines and homeless dogs, no document was found on organizations working in most ruminants, camels, and poultry at all. Most of the present works indicated, as there are wide violations of the animal right developing world including Ethiopia. Developing nations like Ethiopia need to develop systems to inspect animal facilities and review research practices to ensure that animal welfare issues well addressed in all institutions and facilities dealing with animals remain basic concern. Frequent updating the current public thoughts, believes about the importance of practicing good animal welfare management and applying legislative actions will be important in animal production systems especially in developing countries like that of Ethiopia, where the poor animal welfare is enormous.
\end{abstract}

Keywords: Animal welfare; Developing; Ethiopia; Freedoms; Legislations

\section{Introduction}

Animal welfare is a multi-faceted issue, which implies important scientific, ethical, economic and political dimensions [1]. Animal welfare as a 'formal discipline' started with the publication of the Brambell report on the welfare of farm animals, issued by the British government in 1965 [2]. The study of animal welfare includes husbandry and human-animal interactions, the multi-faceted approach has to include collaboration between the natural and social sciences [1].

Animal welfare issue encompassed domestic (farm, game and pet) [3], wildlife (undomesticated, free ranging terrestrial vertebrates (reptiles, amphibians, birds, and mammals)) [4,5] laboratory and aquatic animals [6-8].

Farm animal welfare concern is limited in developing countries compared to developed nations. The farm animal welfare concerns can be seen from viewpoints they are kept and management practices, mainly in systems where animals are kept in confinement for most of their lives, feeding methods, health care situations, and expression of their normal behaviors [8].

The use of an ethical basis for animal welfare standards requires some generally accepted principles on how animals should be treated and used by humans. In general, animals have enormous capacity to feel a huge range of emotions, to learn from their experiences, to adapt to challenges, and to suffer when their needs are either ignored or disrespected. It is now time, in the evolution of the relationship between humans and animals, to move forward with this knowledge and take real action to improve the lives of farm animals. The use of behavioral principles should improve efficiency of livestock handling and reduce stress on animals. Changing public opinion about the importance of good animal welfare and applying legislative actions will be important in animal production systems especially in developing countries where the poor animal welfare is immense and production management is below sub standards $[3,8]$.

The status of animal welfare keeping is variable between developed and developing world. The source of differences arises due to there is a difference in the interest of policy makers between developed and developing nations in driving up of consumers to demand products passing animal welfare standards [9].

Now days, animal welfare issues are going on well under better pressure in the western parts of the world contrary to the developing countries where by animals poorly handled or below the standard due to misconception and resource scarcity or limitation. In developing world, it is common to see poor handling and welfare status of farm animals, which is below the standards [3] because of misconception and resource scarcity in the nations [10]. The concern of animal welfare is showing improvement and obtaining a better attention in 
farm animal welfare, which probably linked to the increased production costs and reduced productivity production [11]. There are for instances policies such as, restricting imports of livestock products by insisting on domestic animal welfare standards risks encroaching on international trade agreements [11]. Therefore, policy developers in western parts of the world have reflected an increasing concern in strategies where consumer demand for animal welfare-outgoing products is expected to boost animal welfare standards [9].

Taking Ethiopia as one of the developing country, there is no a comprehensive animal welfare legislation, which protects animals' right except few articles present in criminal laws of the country presented since Emperor King Minilik II [12]. The country tried to articulate the animal welfare issues since 1889 when the first Italian Veterinary Mission came to Ethiopia to study the impact of the disease in the country. Among the first 7 Ministries established by Emperor King Menelik II in 1907, the Ministry of Agriculture and Works was one of them which later on were split in to Agriculture and Works ministries. During that time, the main focus of the Ministry of Agriculture was on animal health; with this background the work amplified by the French Government in conducting cattle vaccination programs in the country through its Veterinary Mission for 6 years starting from 1908-1914. Even during the Italian occupation of the country, animal health services were provided in, around Addis Ababa, and in some provinces of the country. During this time, a veterinary diagnostic laboratory was established at "Kechene Medhaniaslem" in Addis Ababa and it was producing vaccines for some livestock diseases. The country tried to pass two proclamations about animal welfare, called as Animal welfare notice No. 187/1947 ET and Endemic animals' welfare regulation No. 191/1947 ET [12]. There were also other diseases prevention proclamations, which indirectly relate to the animal welfare in the country. Even though the countries have developed various welfare regulations and notices, the welfare remained below standard. With this as a background, this paper highlighted on the general status of animal welfare in developing countries with the reference of Ethiopia.

\section{Measuring of animal welfare}

To talk about animal welfare it is crucial to see it from perspectives such as biological, affective and natural state point of view. Even though currently it is not able to develop a unified definition of the desirable welfare state adapted, the above three points of perspectives can be used as a base. According to Mellor et al. [13], the above three perspectives are clarified as follows. The biological state: describes the animals' health growing and reproduction situation as a parameter of welfare; the affective state: stresses potential for animals to suffer or to have positive experiences and the natural state compares the differences between captive animals and the wild state where they origin from, and to what extent they are able to express natural behaviors.

When one observes injuries signs, such as self-mutilation, or chronic stimulation of the autonomic nervous system indicates clearly as there is a lowered animal welfare. In another approach, welfare of an animal said in good conditions when stress responses not chronically activated and when the individual can cope with them successful [14].

Other fundamental bases for maintaining animals welfare sustainability are the five freedoms outlined in the 1970s in England and have since then been the central basis for animal welfare all over the world according to FAWC [10]. These five freedoms includes
(1) Freedom from hunger and thirst by providing constant access to fresh water and a diet to maintain full health and vigor

(2) Freedom from discomfort; by providing an appropriate environment including shelter and a comfortable resting area

(3) Freedom from pain, injury, or disease: by prevention or rapid diagnosis and treatment;

(4) Freedom to express normal behavior: by providing sufficient space, proper facilities, and company of the animal's own kind; and

(5) Freedom from fear and distress: by ensuring conditions and treatment, that avoids mental suffering.

It is true that ranges of animal's behaviors that an animal's expressions are good indicators of how the animal copes with certain situations. If one observes behavioral changes as when the animal refuses to move or vocalize in a high extent or different sound, these may indicate the extent of the problem, where the situation can be improved, or in need of better condition [14].

\section{Animal Welfare in Developing Countries}

From the beginning of civilization draught animals, bullocks, horses, camels, mules, donkeys, etc., have been making a significant contribution to society. Many draught animals (DAs) used for plough in developing countries. For instance in India more than two million people are dependent on DAs for ploughing, for pulling vehicles, and for carrying goods. For a variety of reasons the developing countries of the world may have to depend on Draught Animal Power (DAP) for many more years to come. The DAs plough 100 million hectares of land and haul 1,800 million tonnes of freight in 15 million animal drawn carts $[15,16]$.

The developing countries of Asia poultry farming welfare for instance started typical factory farming system with intensive deep either litter or battery cages from 1965 onwards. Three quarters of the world's 4,700 million egg-laying hens are confined in tiny battery cages. In India about $60 \%$ of which are in battery cages [17]. Broiler chickens under six weeks old suffer painful crippling due to fast growth rates, whilst one in a hundred of these very young birds die of heart failure.

In Africa nearly to 300 million people, depend on livestock for their income and livelihood, which is inseparable in the daily way of life and activity. In spite of the fact, there is little or no provision for animal welfare is made in the laws and regulations of most African countries $[18,19]$. Many study results showed that animal welfare concern remain at its lower level in developing countries due to various reasons, some of the key factors that hinder the welfare issue includes, poor economic of the people [20] absence of government support, and lack of skills towards the management [21].

However, from recent onwards, due to the World Organization for Animal Health (OIE) Performance of Veterinary Services (PVS) Tool includes animal welfare as a critical competency in Veterinary Services, and most African countries have now conducted PVS appraisals. All relevant parties are developing animal Welfare Strategy in the regional system of Africa, which will provide opportunities for full engagement. Without a level of understanding of animal welfare that is sufficient to support clear animal welfare policy development and implementation, problems may appear in the near future, which could jeopardize the attainment of increased animal productivity and product quality, which may have negative implications for economic growth and for national, and international trade [19]. 
Slaughtering places (houses) for instance in Africa are the commonest places of deprivations of animal welfare as indicated by Masiga and Munyua [5], where abattoirs confront the definitions of slaughter houses, other unacceptable procedures such as cutting of tendons, stunning animals with mattocks, strangling chickens, suffocating pigs, and slitting the throats of animals and birds before stunning.

\section{Animal Welfare in Developing Countries: The Case of Ethiopia}

\section{Ethiopian livestock population}

According to the Central Statistics Agency (CSA), the livestock population of Ethiopia is estimated to be about 52.13 million cattle, 24.2 million sheep, 22.6 million goats, and about 0.99 million camels in the sedentary areas of the country. The total poultry population at country level estimated to be about 44.89 million. Result of the survey revealed that about 5.0 million hives estimated in the rural sedentary areas of the country. Ethiopia has the third largest equine population in the world, with roughly 9 million horses, donkeys and mules, serving as a lifeline for $85 \%$ of Ethiopians and playing a crucial role in the national economy (http://www.afid.org.uk/countries/Africa/ Ethiopia/The+Brooke).

Ethiopia is a country that has a high level of diversity in the agriculture [22] with the largest livestock populations in Africa. Despite the fact Ethiopia is developing and the economic condition improving steadily, animal welfare is a subject that so far has not gained much attention until now, in which animals are subjected to live under harsh conditions and disrespecting their natural behavior (http://www.afdb.org/en/countries/east-africa/ethiopia/ethiopiaeconomic-outlook/; Masiga and Munyua; http://www.afid.org.uk/ countries/Africa/Ethiopia/The+Brooke).

\section{Animal welfare awareness in Ethiopia}

Than ever before animal welfare, issues become a worldwide topic under new focus currently. Comparing the world nations, the western hemisphere of the world follow strict animal welfare regulations and similarly organizations are fighting for animals' rights in a society where economics often deemed the most important factor. In contrary to the western hemisphere, there are no compressive animal welfare regulations or any related constitution that protects them from suffering in Ethiopian condition in general [10].

According to Homeless Animal Protection Society in Ethiopia (HAPS) [22] report, in Ethiopia there are six to seven organizations working for animals' welfare. The first organization first established as early as 1954 in Bale, Southeastern Ethiopia area with the "Bale mountains national park" (BMNP), where the 1st idea of assisting homeless dogs started. This society mainly working in humanely reduce the number of homeless dogs through applying animal birth control program by trap neuter release (TNR) method together with vaccinating against rabies in order to save the endangered Ethiopian wolf from threat of extinction, rabies, and hybridization of domestic dogs. The idea of this society is emanated due to the measures used to be taken in the BMNP primarily, to eliminate homeless dogs and secondly to save the endangered Ethiopian wolves from rabies and hybridization. The measures used to solve the problems were shooting and poisoning which never helps to solve the problem despite the fact it has been practiced for the past several years. The method used to reduce the homeless dogs in the area was against animal welfare. According to HAPS [23], few of the park staffs who noticed the cruelty and ineffectiveness of the above mentioned measuring methods from their past experience decided to establish this society in order to solve the problem and save the animals from cruel activities and also from extinction as well. BMNP then started promoting animal welfare and right mainly via community education and then try to reduce the suffering of homeless dogs through vaccination and neutering.

Despite the fact the idea and the start dealing with animal welfare goes back to 1900's in Ethiopia, still it has not yet been accomplished the main objectives of its work to be exercised. Few years before, it showed a progress and that hopefully will be ready within near future [24]. The Establishment of the new Ministry of Livestock and Fisheryin Ethiopia by 2015, focused on mainly increasing the production of livestock to contribute up to $10 \%$ of the Gross Domestic Product (GDP) according to The Ethiopian herald news report [25]. This new Ministry office will hopefully contribute for the emanating of comprehensive animal welfare legislations and issues in the country in the future, which is a good opportunity, as this fact mentioned previously by Masiga and Munyua, Bahari et al. and Steinfeld et al. [5,26-28] that supports there is high production after keeping animal welfare properly.

The World Organization for Animal Health (OIE) implemented the first international guidelines for animal welfare in earlier in 2005 and about a total, 167 countries accepted these OIE [26]. The five freedoms that mentioned earlier outlined in the 1970s in England, are fundamental basis for animal welfare all over the world [10]. Nevertheless, there is still a lack of guidelines and regulations for animal welfare in Ethiopia [29].

\section{Animals welfare problems in Ethiopia}

In Ethiopia, animal welfare problems mostly seen in marketing places, during transporting, farming places, abattoir (slaughtering) houses, feeding areas, sheltering areas and watering places [30]. Ethiopia has several marketing systems existing for trading animals in different locations.

Transporting to markets mostly done in Ethiopia by trekking just like most African countries, due to lack of suitable vehicles, and there has been a research performed on how many animals die and injured during transport $[5,31]$. It has been shown that, transport conditions, level of vibration on vehicle and the behaviors the animal expresses and changes of stress hormones, contradict animal welfare largely [31]. The common challenge in walking animals by foot often leads to accidents such as injured, dead or stolen of animal's cases, which were investigated by Bulitta et al. [31] who found that $7.6 \%$ of animals died, 6-9\% got injured and $2.8 \%$ were stolen. Likewise, lameness and injuries such as swelling of legs commonly occur. Similarly, the above has also been proven a problem when animals are also transported by vehicle [5] indicating the problems which accompany a lack of rest, water and feed.

Mostly the handling of animals in developing countries has been an issue of subject for critical discussion since a long many times before and is in need of further research. As indicated by Bulitta et al. [31] stakeholders in Ethiopia handle animals in a bad way, which increased the prevalence of death and injuries [31]. By measuring behavioral or physiological conditions, animal handling can be explained to a higher extent and a welfare concept implemented in the particular area. For instance when adult male cattle are mixed in large or during transport, 
they express higher levels of fighting behavior which can be recorded and measured as a poor welfare indicator. Farm animals can remember the previous challenging situation during transport or handling by the stakeholders, where a larger hesitance reflected by the animals indicate, the greater the previous bad exposer that must have been experienced [32].

In this regard animal welfare situation in Ethiopia has multi directional problems that have not been dealt by the stakeholders and not covered even by the present non-governmental organizations working with this issue. In Ethiopia, farm animals such as oxen generally subjected to plough for long period without having rest and supplied adequate feed and water [33]. Pack animals such as horses and donkey are forced to carry overload weight for long distances without proper harnessing materials and inadequate feed and water provisions, despite their contributions is high in the daily activity of the owner directly or indirectly [33]. Pet animals such as dogs will be killed by poison inhumanly yearly for the sake of rabies control and prevention in most areas of the country [34]. Sick animals will not be taken to clinics for treatment. The farm animals in most parts of the country are openly housed without appropriate shelter and are exposed for intensive direct sunlight and erratic summer rainfall. Animals will be forced to stay for long time in the market even for days without water and feed in harsh handling manner. However, a number of Veterinary schools and Animal science fields of study departments are graduating professionals yet the services in health care and keeping the welfare of animals is lagging behind the expectation.

\section{Regulations and rules in Ethiopia with respect to animal welfare}

As any African countries, Ethiopia has not formulated regular ways of awareness creation to the public and is not aware of what the minimal animal welfare standards to be esteemed. There are few attempts made by few non-governmental organizations such as The Donkey Sanctuary Project, Homeless Animals Protection Society [35] introduction of Animal welfare to the curriculum of animal science and veterinary medicine fields of study from the government side [33]. It is true most proportions of Africans Livestock owners do not realize as animals are sensitive to beatings and mistreatment. In addition, many of them make branding or knives in order to identify their animals on prominent parts of the animal body [36].

Ethiopia as a country participated in development of animal welfare strategy and guidelines in IGAD-wide conferences. The IGAD conference dealt issues like developing relevant policy, national legislations and clear strategies on animal welfare matters, adoption of the existing international animal welfare standards in a science based animal welfare standards and guidelines. Ethiopia also move a good step in integrating the animal welfare issues in the educational system (curriculum) in particular in at the university level, specifically in veterinary and animal science fields of study [36].

Ethiopia support and facilitate the exercise of animal welfare, it has the legal frame in encouraging active participation of animal science professionals in the activities of animal welfare institutions through membership and active participation by offering advice, professional services, to these organizations and/or their representatives [36].

In Ethiopian, various proclamations tried to show as it condemn aversive actions done on animals. For instance, crime proclamation No.414/2004 of Ethiopia stated that contamination of water, feed and pasture counted as a crime. Crimes committed through production and distribution of substances hazardous to animal health, manufacture, adulteration and sale of fodder and products injurious to livestock and scandalous treatment of animals are included indicating animal welfare issues lightly in different articles on the Criminal Code of the Federal Democratic Republic of Ethiopia [37].

Federal Negarit Gazeta of Ethiopia under the Proclamation No. $267 / 2002$ stated about the prevention and control of animal diseases. In this proclamation, the primary concern is to prevent and control animal diseases in order to maximize the benefits obtained from the extensive livestock resource by keeping the wellbeing or welfare of animals $[38,39]$. Whereas the Civil Society Organization stated as the Ethiopian government promotes nongovernmental societies to organize and work on animal welfare issues in the state.

Ethiopian Veterinary Drug and Feed Administration and Control Proclamation No. $728 / 2011$ also stated as clinical test shall be conducted with due care to animal welfare requirements [38].

\section{Non-governmental organizations activity in Ethiopia}

At present time, few non-governmental organizations are working for wellbeing and welfare animals. They mainly focus on homeless and/or injured animals [24]. Most of the current non-governmental organizations mainly engaged working one quines and some onhomeless dogs. No document was found on organizations working in most ruminants, camels, and poultry at all.

\section{Overview of researches done on major animal welfare problems in Ethiopia}

A study done by Kumar et al. [40] in Mekelle city Northern Ethiopia on donkey showed that as they are forced to work under poor body conditions and having wounds in the body parts of donkey. The research indicated that the donkeys' wound also associated with the work type they are performing. Based on other study done by Mekuria et al. [41] in Hawassa town equids were shown a poor welfare situation in the area. Equids were highly subjected for intense draft, packing condition as a result, it is injuries, wounds were observed at tail, ribs, breast, and hindquarters while at the same time, rubber shoeing was found to be of poorest quality, thus leading to high slip hazard in Hawassa town. The lesions indicated above associated with work type and body condition show that working equids experience multiple welfare problems in general. Another study at Meskan District by Mekuria and Abebe [42] in southern Ethiopia showed equines forced to work frequently without proper care and handling in body conditions, having lesions in different body parts. Another study done by Jerlström [43] also showed that animals are transported for long distances and durations to the markets. A study by Bulitta et al. [31] on Animal Handling during Supply for Marketing and Operations at an Abattoir in Developing Country: The Case of Gudar Market and Ambo Abattoir, Ethiopia revealed there were no appropriate vehicle and loading facilities and animal handling conditions were poor in general. Lameness and injury to bone, muscle, swelling of leg and sickness were widely observed during transportation by walking. Poor market infrastructures; lack of regional abattoir facilities; difficulties in getting timely market information; and lack of well-organized networks between stakeholders were also identified as existing problems compromising the animal welfare and economic benefits, besides Bulitta et al. [31] also showed significant number of deaths, injury and stolen cases seen in Gudar Market. Mandefro [44] reported from a study on harnessing problems of working donkeys in Sidama zone as 
Page 5 of 6

ill-fitting and improperly made tail straps that usually has sharp edge, causes lesions on the underneath of the base of tail of working donkeys. Masiga and Munyua [5] showed the most common transport system is by foot dependent on the low level of appropriate vehicles in Ethiopia.

Amante et al. [45] reported from Nekemte Town, East Wollega Zone, Ethiopia management constraints like feed shortage, traditional health care, lameness, wound, overworking, overloading, housing problems and different cruelties on the animal together with the occurrence of trypanosomosis, parasitism, pneumonia, physical injuries, neglect and general maltreatment in the area on equines. Regarding feeding practices of farmers to their working equines Dinka et al. reported that almost $46 \%$ of them feed them once per day which is below the standard handling of animals [46-48].

\section{Conclusions}

The issue of farm animal welfare in developed world has a great attention nowadays. The concern normally based on the animals natural freedoms and respecting their right focusing on how animals are kept and managed. Regarding the five freedoms of animals, it is the primary concern and is an essential minimum standard in practicing welfare. The place where animal welfare frequently violated such as market places, transporting methods, abattoir, houses and the like should get a serious focus primarily. Giving legal support and facilitating for non-governmental organizations to engage in animal welfare works should continue at large scale in holistic approach to include all species of farm animals. More research in the identification of the welfare problems in the country should continue by including all farm animals and pets. This review identified, as there are less concern about animal welfare in Ethiopia in general, in which no compressive legislation, rules or regulations formulated to protect animals' rights, that indicates there is poor productivity among the livestock in the country. Farm animals will give the maximum product only when their rights and wellbeing respected. In addition, education and enforcement of premier management practices associated with livestock handling for concerned groups are inevitable. Developing nations like Ethiopia need to develop systems to inspect animal facilities and review research practices to ensure that animal welfare issues are addressed well in all institutions and facilities dealing with animals remain basic concern. Frequent updating the current public thoughts and believes about the importance of practicing good animal welfare management and applying legislative actions will be important in animal production systems especially in developing countries like that of Ethiopia, where the poor animal welfare is enormous. Based on the above literature reviews the following recommendations are forwarded;

It is recommended that legislation should be emanated and practiced based on the OIE standards:

Societies are encouraged to work on other farms animals besides equines and homeless,

The Basic concept of animal welfare should go deep into farmers and farm owners level to have the basic concept,

Animal Welfare issue should also need to go deep into the community, primary and secondary schools level for better understanding,

It is necessary to include stakeholders in the livestock trade on animal welfare issues in order to get their support and compliance,
Local administrates and governors need to customize rules and regulation to endorse animal welfare in areas like abattoir, marketing places, transportation and handling of homeless and injured animals.

\section{References}

1. Lund V, Coleman G, Gunnarsson S, Appleby MC, Karkinen K (2006) Animal welfare science Working at the interface between the natural and social sciences. Appl Anim Behav Sci 97: 37-49.

2. Brambell (1965) Report of the Technical Committee to enquire into the welfare of animals kept under intensive livestock husbandry systems. Her Majesty's Stationery Office, London, UK.

3. FAO (2011) Legislative and regulatory options for animal welfare. FAO Legislative Study, p: 104.

4. Yarrow G (2009) Wildlife and Wildlife Management. Clemson Extension. Forestry and Natural Resources.

5. Masiga WN, Munyua SJ (2005) Global perspectives on animal welfare: Africa. Rev Sci Tech 24: 579-587.

6. Laboratory Animal Welfare Act (1966) PL, pp: 89-54.

7. NWRC (2009) Improving Wildlife Welfare. USDA, APHIS, WS.

8. Farm Animal Welfare (2014) Farm Animal Welfare, Past Present and Future. Commissioned by The RSPCA's Freedom Food Scheme to Mark Its 20th Anniversary: A Review of Farm Animal Welfare in The UK. The Food Ethics Council and Heather Pickett.

9. Désiré L, Boissy A, Veissier I (2002) Emotions in farm animals: a new approach to animal welfare in applied ethology. Behav Processes 60: $165-180$.

10. FAWC (2011) Farm Animal Welfare Committee. UK Government.

11. Fraser D, Duncan IJH (1998) 'Pleasures', 'Pains' and animal welfare: toward a natural history of affect. Anim Welfare 7: 383-396.

12. APHRD (2009) Ministry of Agriculture and Rural Development Animal and Plant Health Regulatory Directorate. Ethiopia Freed from the most dangerous Cattle disease, Addis Ababa.

13. Mellor DJ, Pattersson-Kane E, Stafford KJ (2009) The Science of Animal Welfare. Singapore: Wiley-Blackwell, UFAW Animal Welfare Series.

14. Blokhuis H (1998) Studies of Stress in Farm Animals. Comparative Haematology International 8: 94-101.

15. Aradom S (2012) Animal Transport and Welfare with special emphasis on Transport Time and Vibration. Acta Universitatis agriculturae Sueciae.

16. Ramaswamy NS (1984) Indian animal drawn vehicles and interdisciplinary survey of the state of the art, designs and operations. Indian Institute of Management, Bangalore, for Department of Science and Technology, Government of India.

17. Rahman SA, Walker L, Ricketts W (2005) Global perspectives on animal welfare: Asia, the Far East, and Oceania. Rev Sci Tech 24: 597-612.

18. Callaghan J (2003) The welfare of farm animals in Europe: current conditions and measures. In Proc 2nd International Seminar on animal welfare, organized by Commonwealth Veterinary Association and World Society for the Protection of Animals, 14-16 February, Bangalore, India. Commonwealth Veterinary Association, Bangalore, pp: 55-62.

19. Molomo M, Mumba T (2014) Drivers for animal welfare policies in Africa. Rev Sci Tech 33: 47-53.

20. Sullivan AO, Sheffrin SM (2003) Economics: Principles in Action. Pearson Prentice Hall, New Jersey, USA, p: 471.

21. Talha EA (2014) Poultry Welfare in Developed and Developing Countries. Animal and Veterinary Sciences 2: 1-4.

22. Stock F, Gifford-Gonzalez D (2013) Genetics and African Cattle Domestication. Afr Archaeol Rev 30: 51-72.

23. HAPS (2006) Homeless Animals Protection Society. Annual Report.

24. Bekele $\mathrm{T}$ (2009) An overview on animal welfare situation in Ethiopia. Addis Ababa, Ethiopia.

25. The Ethiopian Herald (2015) Increasing livestock GDP contribution. The Ethiopian Herald, Addis Ababa, Ethiopia. 
Citation: Asebe G, Gelayenew B, Kumar A (2016) The General Status of Animal Welfare in Developing Countries: The Case of Ethiopia. J Veterinar Sci Techno 7: 332. doi:10.4172/2157-7579.1000332

Page 6 of 6

26. Bahari MM, Maiseli NG, Mruttu HA, Joseph W (2006) Animal welfare advocacy and veterinary profession: Tanzania experience. Proceedings of the 24th TVA Scientific Conference, Arusha, Tanzania.

27. Bahari MM, Maiseli NG, Mruttu HA, Nsiima N, Shirima JM (2006) Animal welfare and improved productivity. Proceedings of the $32 \mathrm{nd}$ TSAP Scientific Conference, Arusha, Tanzania.

28. Steinfeld H, Gerber P, Wassenaar T, Castel V, Rosales M, et al. (2006) Livestock's long shadow: environmental issues and options. Food and Agriculture Organization of the United Nations, Rome.

29. OIE (2005) Terrestrial Animal Health Code: Transport of animals by land. World Organization of Animal Health.

30. Bulitta F (2007) Effects of handling on animals' welfare during transport, Licentiatehesis. Department of Energy and Technology. The Swedish University of Agricultural Sciences, Uppsala, Sweden.

31. Bulitta F, Gebresenbet G, Bosona T (2012) Animal Handling during Supply for Marketing and Operations at an Abattoir in Developing Country: The case of Gudar market and Ambo Abattoir, Ethiopia. Journal of Service Science and Management 5: 59-68.

32. Broom DM (2000) Does present legislation help animal welfare Sustainable animal production: Workshops.

33. FAO (2014) The role, impact and welfare of working (traction and transport) animals. Animal Production and Health, Rome.

34. Deressa A, Ali A, Beyene M, Selassie BN, Yimer E, et al. (2010) The status of rabies in Ethiopia: A retrospective record review. Ethiop J Health Dev 24: 127-132.

35. http://www.afdb.org/en/countries/east-africa/ethiopia/ethiopiaeconomic-outlook/

36. Ministry of Agriculture and Rural Development (2010) Country Position on Regional Policy Framework on Animal Health, For Trade and Poverty Reduction. Federal democratic republic of Ethiopia, Addis Ababa.

37. The Criminal Code of the Federal Democratic Republic of Ethiopia (2005) The Criminal Code of the Federal Democratic Republic of Ethiopia. Proclamation No.414/2004, Addis Ababa, Ethiopia.
38. Federal Negarit Gazeta of The Federal Democratic Republic of Ethiopia (2011) A Proclamation To Provide For Veterinary Drug And Feed Administration and Control. Addis Ababa, Ethiopia.

39. Federal Negarit Gazeta of the Federal Democratic Republic of Ethiopia (2002) National Legislative Bodies / National Authorities, UNHCR.

40. Kumar N, Fisseha KK, Shishay N, Hagos Y (2014) Welfare Assessment of Working Donkeys in Mekelle City, Ethiopia. Global Veterinaria 12: 314-319.

41. Mekuria S, Mulachew M, Abebe R (2013) Management practices and welfare problems encountered on working equids in Hawassa town, Southern Ethiopia. J Vet Med Anim Health 5: 243-250.

42. Mekuria S, Abebe M (2010) Observation on major welfare problems of equine in Meskan district, Southern Ethiopia. Livestock Research for Rural Development 22: 3.

43. Jerlström J (2013) Animal welfare in Ethiopia: Transport to and handling of cattle at markets in Addis Ababa and Ambo. SLU.

44. Mandefro A (2008) A study on harnessing problems of working donkeys in Sidama zone. DVM Thesis, Addis Ababa University, Faculty of Veterinary Medicine, Debre-Zeit.

45. Amante M, Hunde A, Endebu B, Hirpa E, Mamo B (2014) Health and Welfare Assessment of Working Equine in and Around Nekemte Town, East Wollega Zone, Ethiopia. American-Eurasian Journal of Scientific Research 9: 163-174.

46. Dinka H, Shelima B, Abalti A, Geleta T, Mume T, et al. (2007) Socioeconomic importance and management of carthorses in the mid rift valley of Ethiopia. In: Pearson RA, Muir CJ, Farrow M (eds.). The Future for Working Equines. The fifth International Colloquium on Working Equines, pp: 181-188.

47. Amanfu W, Maina JA, Stratton J (2011) OIE - PVS Evaluation Report of the Veterinary Services of Ethiopia. World Organization for Animal Health, Paris, France.

48. Mengistu A (2006) Country Pasture/Forage Resource Profiles. FAO, pp: 5-35. 